\title{
Morbidly adherent placenta: management is real challenge
}

\author{
Rupa C. Vyas, PrinceNrutik Amrut Patel*, Sapana Shah, Shweta N. Vala, Nidhi B. Patel
}

Department of Obstetrics and Gynecology, NHL Municipal Medical College, Ahmedabad, Gujarat, India

Received: 07 January 2019

Accepted: 05 February 2019

\section{*Correspondence:}

Dr. PrinceNrutik Amrut Patel,

E-mail: princenrutik25@gmail.com

Copyright: (c) the author(s), publisher and licensee Medip Academy. This is an open-access article distributed under the terms of the Creative Commons Attribution Non-Commercial License, which permits unrestricted non-commercial use, distribution, and reproduction in any medium, provided the original work is properly cited.

\begin{abstract}
Background: The objective of the present study was to describe management of morbidly adherent placenta with placenta previa and feto-maternal outcome.

Methods: All antenatal USG diagnosed cases of morbidly adherent placenta were analyzed. The cases were managed by elective caesarean hysterectomy and non-separation of placenta at delivery. Amount of blood loss, blood transfused, ICU admission, postnatal complications and hospital stay was recorded.

Results: From January 2010 to October 2018, 22 cases of morbidly adherent placenta were diagnosed on gray scale and color Doppler during antenatal ultrasound scan. Scheduled caesarean hysterectomy without attempting placental removal was done. Subtotal hysterectomy was performed in $17(77.2 \%)$ cases and total hysterectomy in remaining $5(22.8 \%)$ cases. All the patients required blood transfusion. Seven $(31.8 \%)$ patients had urinary bladder injury. One case developed DIC and One needed ventilatory support. No patient died in this series.

Conclusions: Antenatal diagnosed cases of morbidly adherent placenta, avoidance of placental separation and caesarean hysterectomy results in better maternal outcome.
\end{abstract}

Keywords: Caesarean hysterectomy, Feto-maternal outcome, Morbidly adherent placenta

\section{INTRODUCTION}

Morbidly adherent placenta is known to be related with remarkable maternal morbidity and mortality. ${ }^{1}$ Woman with placenta praevia has a $3 \%$ risk of placenta accreta. An increased incidence over the recent years may be secondary to the rise in cesarean section rates. There is coinciding effect of placenta praevia and increasing number of cesarean sections: the risk of placenta accreta increases to $4 \%, 11 \%, 40 \%$, and $61 \%$ with one, two, three and four previous cesarean sections respectively. ${ }^{2}$ Recognition of patients with risk factors antenatally is essential for the early diagnosis and management. Diagnosis can be attained by ultrasonography or MRI in the larger number of cases. In cases of morbidly adherent placenta, placental separation at delivery may result in severe haemorrhage and ultimately the need for emergency cesarean hysterectomy. ${ }^{2}$ Moreover, morbidity such as injury to the urinary tract is often encountered during dissection at hysterectomy, when the adherent placenta has invaded the myometrium of the uterine wall to the bladder anteriorly or to the parametrium laterally (placenta percreta) even in elective cesarean hysterectomy. ${ }^{3}$ Significant decrease in blood loss is observed when placental separation is avoided at the time of delivery facilitates bladder dissection from the lower segment. $^{2}$ If the bladder is involved, partial cystectomy could be performed without dissection of the placental tissue at the time of hysterectomy. ${ }^{4}$ However, ureteric injury is more difficult to avoid when the parametrium is involved, even with the use of ureteric stenting. ${ }^{3}$ On the other hand, if the myometrial involvement is partial or focal, separation of the placenta could be effected at delivery with good maternal outcome. ${ }^{5}$ Antenatal diagnosis and assessment of the extent of myometrial involvement may allow anticipation and the planning of management: That is to proceed to conservative 
management or hysterectomy without separation of placenta in cases of extensive myometrial involvement. ${ }^{6}$

The aim of study is to review the usefulness of sonographic criteria in the assessment of the depth of placental myometrial involvement in morbidly adherent placenta. In diagnosed cases of morbidly adherent placenta, antenatal diagnosis and avoidance of placental separation and caesarean hysterectomy result in better maternal outcome.

\section{METHODS}

This was a case series conducted at Obstetrics Departments at our institute from January 2010 to October 2018. 30,050 antenatal women were included in study during this period.

In all women, routine ultrasound scanning at 20 weeks of gestation includes placental localization. Suspected diagnosis of placenta praevia at 20 weeks gestation by transabdominal scan was confirmed by transvaginal scan. Repeat ultrasound (gray scale scan and color Doppler) ultrasound scanning at 32 weeks gestation was done in all women who had low lying placenta at 20 weeks gestation or earlier repeat scan if there was antepartum haemorrhage. In women with major placenta praevia or who have had a previous caesarean section with placenta praevia or an anterior placenta underlying old caesarean section scar are at increased risk of placenta accreta. Diagnostic criteria that suggested placenta accreta, increta, or percreta included $\geq 1$ of the following situations: : $^{1,-10}$

- Placental lacunae: Multiple linear, irregular vascular spaces within the placenta (Swiss cheese appearance)

- Obliteration of clear space: The obliteration of any part of the echolucent area located between the uterus and the placenta.

- Interruption of bladder border: When interruption of the posterior bladder wall-uterine interface occurs; the usually continuous echolucent line appears instead, as a series of dashes. This can give an appearance of intermittent interruptions of the bladder wall uterine interface or an impression that the bladder wall is bulging into the uterine wall.

- Myometrium of less than $1 \mathrm{~mm}$ : In patients who had a previous caesarean delivery and a low-lying anterior placenta, the lower uterine segment has been measured, and it was found that all patients with placenta accreta had a myometrium of less than 1 mm.

Color Doppler showed high velocity and turbulent flow, always associated with placenta accreta.

Women who delivered in second and third trimester with a diagnosis of morbidly adherent placenta were included. In all cases confirmation of morbidly adherent placenta was done by gray scale scan, color Doppler ultrasound, clinical observation at the time of surgery and histopathology. Risk factors for morbidly adherent placenta including previous uterine surgeries and placenta previa were recorded. All patients after antenatal diagnosis of morbidly adherent placenta were planned for elective caesarean section with consent for caesarean hysterectomy. All cases were delivered at 35 weeks except one who presented in 2nd trimester with labor pains and antepartum haemorrhage and had undergone caesarean hysterectomy at 27 weeks. During management of these cases blood loss, need of ICU admission, operative interventions done (hysterectomy, bilateral internal iliac artery ligation, re laparotomy) and length of hospital stay were noted.

\section{RESULTS}

Out of 30,050 women, $322(1.07 \%)$ had placenta praevia diagnosed antenatally by ultrasound scanning. Out of them $22(0.07 \%)$ had morbidly adherent placenta with placenta praevia were diagnosed antenatally with gray scale scan and Color Doppler Ultrasonography.

Out of 22 women with morbidly adherent placenta, all four ultrasound criteria were present in 5 cases and three ultrasound criteria (a, b, d) were present in 17 cases. Six patients had type II anterior placenta praevia, 8 had type III anterior placenta praevia and 8 had type IV central placenta praevia. All cases were antenatally diagnosed by gray scale scan and color Doppler scan and confirmed by histopathology. Six cases were placenta percreta, 10 were placenta increta and 6 placenta accreta. Clinical details are listed in Table 1.

Table 1: Clinical details of patients $(n=22)$.

\begin{tabular}{|l|l|}
\hline Age & Clinical details \\
\hline Maternal age & 22-37 years (mean 32.87 years) \\
\hline Gravidity & $2-6($ mean 3$)$ \\
\hline Parity & $1-6($ mean 3$)$ \\
\hline
\end{tabular}

There were 8 women with previous one caesarean section, 9 with previous two caesarean sections, 4 with previous three caesarean sections and 1 with previous four caesarean sections. Abdomen was opened through vertical incision and lower uterine segment and bladder inspected for extensive vascularity and thinning of lower uterine segment. Delivery of the infant was affected by transverse incision in lower part of upper segment just above insertion of placenta (site of incision decided by USG) and placenta was left un-separated. Cord was clamped and cut near the placental insertion and tied with silk. Bladder was then dissected carefully by blunt and sharp dissection taking care that the large vessels coming in the way were ligated from both ends. Subtotal hysterectomy was performed in 17 cases. Upper segment and involved lower segment with placenta was removed, undilated and uneffaced cervix was left in situ. Total hysterectomy was done in 5 cases, in which cervix was effaced. Placental sinuses were opened up during 
dissection of bladder in all six cases of placenta percreta leading to severe haemorrhage. Maternal morbidity and mortality are listed in Table 2.

Table 2: Maternal morbidity and mortality $(n=22)$.

\begin{tabular}{|l|l|}
\hline Causes & No. (\%) \\
\hline Bladder injury & $7(31.8)$ \\
\hline $\begin{array}{l}\text { Intraperitoneal haemorrhage requiring } \\
\text { relaparotomy }\end{array}$ & $1(4.5)$ \\
\hline DIC & $1(4.5)$ \\
\hline ARDS & $1(4.5)$ \\
\hline Death & $0(0)$ \\
\hline
\end{tabular}

In four $(18.2 \%)$ cases of placenta percreta and three (13.6\%) cases of placenta increta, unintentional bladder injury occurred, which was repaired with polyglactin no3-0 in 2 layers. Approximate blood loss was between $1000 \mathrm{~mL}$ to $1500 \mathrm{~mL}$ in all four cases. All 22 women required blood transfusion ranging from 3 to 24 units (mean 5). One (4.5\%) patient who developed DIC needed 10 units of RBCs, 10 FFPs and 4 Platelet transfusions. All the patients needed blood transfusion ranging from 3 to 24 units (mean 5 units). One $(4.5 \%)$ of the case of placenta percreta continued to bleed intraperitoneally after caesarean hysterectomy and needed re-exploration. There was bleeding from vaginal vault and oozing from bladder base, which was controlled by suturing vaginal vault again and few haemostatic sutures over bladder base. Five (22.7\%) cases required bilateral internal iliac artery ligation to control excessive bleeding. One (4.5\%) patient developed ARDS, needed postoperative ventilatory support for 48 hours. Average hospital stay was 10 days. No maternal mortality occurred.

\section{DISCUSSION}

According to the American College of Obstetrics and Gynecology incidence of morbidly adherent placenta is 1:2500 per delivery. ${ }^{1}$ Morbidly adherent placenta in association with placenta praevia and previous caesarean section delivery is a condition of increasing clinical significance because of the increasing caesarean section rate worldwide. Recent reports suggest its frequency per delivery between 1:2500 and 1:110., ${ }^{2,3}$ The incidence of placenta praevia with morbidly adherent placenta is 1:1365 per delivery in present study. Invasive placental implantation occurs when there is a defect or absence of the decidua basalis, which is replaced by loose connective tissue that leads to direct attachment of the chorionic villi of the placenta to the myometrium. There are 3 forms of abnormal placental invasion, Placenta accreta is mildest and most common form $(75 \%-78 \%)$, it involves contact with the myometrium, and it does not invade into the muscle itself. Placenta increta is a variant that involves the extension of the chorionic villi into the myometrium and occurs in $17 \%$ of cases. Placenta percreta is the most severe variant; the placenta penetrates through the entire uterine wall and may attach to organs in vicinity, such as the bladder or rectum. It occurs in $5 \%$ to $7 \%$ of all cases. The present study includes $20 \%$ placenta accreta, $60 \%$ placenta increta and $20 \%$ placenta percreta.

Etiology and risk factors include "any process or procedure capable of scarring the endometrial cavity," predisposing to anomalous myometrial invasion by the placental villi. These risk factors are grand multiparity, asherman's syndrome, previous cesarean delivery, uterine curettage, myomectomy, or uterine reconstructive surgery (septum resection), placental implantation over a submucosal fibroid located in the lower uterine segment, near the rudimentary uterine horn or near the uterine cornu. ${ }^{2,6}$ Additional risk factors include hypertensive disorders, smoking and a maternal age older than 35 years. ${ }^{2,6}$ The present study includes all cases of morbidly adherent placenta having two high risk factor: History of $\geq 1$ previous cesarean section and placenta praevia.

During pregnancy morbidly adherent placenta may be either asymptomatic or may present with antepartum hemorrhage, abdominal pain and acute abdomen, while intrapartum it may present as retained placenta, postpartum haemorrhage or uterine rupture. The maternal risk appears to occur at the time of placental separation resulting in severe hemorrhage, disseminated intravascular coagulation (DIC), massive blood transfusion requirement, and need for intensive care, hysterectomy and occasionally maternal death. ${ }^{4-6}$ The present study reported antepartum hemorrhage in 14 $(63.3 \%)$ cases and remaining women were asymptomatic. All the women required blood transfusion and postoperative intensive care.

It is essential that morbidly adherent placenta should be diagnosed earlier, and adequate preoperative measures should be taken to reduce its high morbidity and mortality. With the advent of radiological facilities of Doppler ultrasound and MRI, antenatal diagnosis has brought revolution in the management of this cases. ${ }^{1,8,9,10}$ It was reported that grayscale ultrasound had a sensitivity of $93 \%$ and a specificity of $79 \%$ in the diagnosis of placenta accreta. ${ }^{8}$ Two dimensional (2D) color Doppler Ultrasonography has a sensitivity of between $82.4 \%$ and $100 \%$, and a specificity of between $92 \%$ and $96.8 \% .^{1,8}$ The present study confirmed diagnosis of morbidly adherent placenta with grey scale and color Doppler ultrasound in all the cases showing $100 \%$ sensitivity and specificity. Tam et al reported reduced rate of UT injury in cases of antenatal confirmed diagnosis of Placenta Accreta Spectrum disorder (39\% vs. 63\%; $\mathrm{P}=0.04) .11$ The present study reported urinary tract injury in $31.8 \%$ cases. $^{11}$

Universal access to multidisciplinary team (MDT) care includes radiologist, obstetrician, gynaec-onco surgeon, urologist or surgeon, anesthetist, neonatologist, blood bank pathologists, intensivists, interventional radiologist, cell saver and perfusionists for 24/7 access in urgent/emergent situations. ${ }^{12}$ Walker et al reported that 
MDT components were significantly associated with a reduction in composite morbidity. ${ }^{13}$ Latest cohort studies have reported that women managed by MDT care were less likely to need significantly large-volume blood transfusion, ICU admission, and re-surgery within 7 days of delivery as compared to managed by standard obstetric care without a specific protocol. ${ }^{12}$

The ideal time to plan elective cesarean in placenta accreta is conflicting. The collective opinion is to operate between 35 and 38 weeks. The statistics shows rise in complications after week 35 related to placenta percreta having anterior invasions. After 35 weeks, the upper margin of the invasion extends beyond the upper wall of bladder leading to additional disruption in the myometrium with higher risk of bleeding. Furthermore, the dynamic traction of the invaded myometrium during surgery produces variable activation of the coagulation system resulting fibrinolysis responsible for a capillary and continuous hemorrhage that is difficult to manage by either compression sutures or endovascular treatment. Hence, $1 \mathrm{U} / 10 \mathrm{~kg}$ body weight of cryoprecipitate must be infused before the surgery, if preoperative plasma fibrinogen levels $<250 \mathrm{mg} / \mathrm{dl}$. This plays vital role to maintain a stable clot if fibrinolysis already has begun, as both hysterectomy and placental removal generally leads to decline in fibrinogen levels to between 100 and 200 $\mathrm{mg} / \mathrm{dl} .^{14}$

The most influential variable on maternal outcome is not attempting to remove the placenta as it leads to uncontrolled hemorrhage. ${ }^{12}$ A retrospective study by Yap et al showed placental removal before hysterectomy resulted in increased maternal morbidity. ${ }^{15}$

According to FIGO consensus guidelines, in the setting of planned cesarean hysterectomy for Placenta Accreta Spectrum disorders, no attempt at manual separation of placenta should be undertaken because leaving it in situ is associated with lower blood loss. ${ }^{12}$ Antenatal diagnosis, scheduled caesarean hysterectomy without attempt of placental removal reduced maternal morbidity, as seen in present study. Fundal incision for delivery of the infant allows non-separation of placenta and consequently less postpartum hemorrhage.

The survey of the Society for Maternal Fetal Medicine (SMFM) specialists regarding their management of PAS disorders reported that $55 \%$ of all providers performed total hysterectomy and $45 \%$ performed supracervical hysterectomy.16 The present study reported total hysterectomy in $22.8 \%$ and subtotal hysterectomy in $77.2 \%$ cases. Tam et al suggested that subtotal hysterectomy may not be effective in the management of PAS disorders with cervical involvement and the preferred option should be a total hysterectomy. In addition, subtotal hysterectomy has not been shown to provide protection against urinary tract injury compared with total hysterectomy in surgeries for PAS disorders. ${ }^{11}$
Hysterectomy has traditionally been advised in the management of placenta accreta but there has been a recent movement towards conservative management and preservation of fertility. Strategies include leaving the placenta after caesarean delivery with surgical uterine devascularization and delayed scheduled hysterectomy, embolization of the uterine vessels, uterine compression sutures and / or over sewing of the placental vascular bed. ${ }^{17} \mathrm{~A}$ conservative approach was first described by Arulkumarran and colleagues in 1986 by using systemic methotrexate. ${ }^{18}$ But it is no longer recommended, as methotrexate is unlikely to have effect on degenerating tissue and resolution completes by 3-4 months regardless its use. ${ }^{19}$ Severe intrauterine infection and life threatening hemorrhage can occur requiring emergency hysterectomy, thus such patients should be carefully monitored and extensively counseled regarding risks. ${ }^{20}$ Localized excision of uterine wall along with adherent placenta and suturing the uterine defect helps to preserve fertility. This is done by inverting the uterus in order to provide good access to the placental site. If area of placental attachment is focal and the majority of the placenta has been removed, then a "Wedge resection" of the area can be performed. ${ }^{21}$

\section{CONCLUSION}

Placenta accreta and its variants, placenta increta and placenta percreta, are rare complications of human placentation that may threaten maternal life due principally to their potential for massive haemorrhage. Its incidence is rising due to the increasing caesarean rates worldwide. Our experience underscores the importance of making the diagnosis antenatally. Favourable outcome can only be achieved with preoperative multidisciplinary input and perioperative measures require adequate time in order to be instituted.

\section{Funding: No funding sources \\ Conflict of interest: None declared \\ Ethical approval: The study was approved by the Institutional Ethics Committee}

\section{REFERENCES}

1. Wh TE. Ultrasonographical features of morbidly adherent placentas. Singapore Med J. 2007;48(9):799-802.

2. ACOG committee on obstetric practice. ACOG committee opinion. Number 266, 2002; Placenta accreta. Obstet Gynecol. 2002; 99(1):169-70.

3. Morken NH, Henriksen H. Placenta percreta two cases and review of the literature. Eur $\mathrm{J}$ Obstet Gynecol Reprod Biol. 2001;100(1):112-15.

4. $\mathrm{Wu}$ S, Kocherginsky M, Hibbard JU. Abnormal placentation: twenty-year analysis. Am J Obstet Gynecol 2005;192(5):1458-61.

5. Clark SL, Koonings PP, Phelan JP. Placenta praevia/accreta and prior cesarean section. Obstet Gynecol. 1985:66(1):89-92. 
6. Usta IM, Hobeika EM, Musa AA, Gabriel GE, Nassar AH. Placenta praevia-accreta: risk factors and complications. Am J Obstet Gynecol 2005;193(3 Pt 2):1045-49.

7. Placenta Praevia, Placenta Praevia Accreta and Vasa Praevia: Diagnosis and Management. RCOG Greentop guideline No 27, 2011:1-26.

8. Finberg HJ, Williams JW. Placenta accreta: Prospective sonographic diagnosis in patients with placenta praevia and prior caesarean section. J Ultrasound Med. 1992;11(7):333-43.

9. Comstock CH, Love JJ Jr, Bronsteen RA, Lee W, Vettraino IM, Huang RR, Lorenz RP. Sonographic detection of placenta accreta in the second and third trimesters of pregnancy. Am J Obstet Gynecol. 2004;190(4):1135-40.

10. Wong HS, Cheung YK, Strand L, Carryer P, Parker $\mathrm{S}$, Tait $\mathrm{J}$ et al. Specific sonographic features of placenta accreta: tissue interface disruption on grayscale imaging and evidence of vessels crossing interface-disruption sites on Doppler imaging. Ultrasound Obstet Gynecol. 2007;29(2):239-40.

11. Tam Tam KB, Dozier J, Martin JR JN. Approaches to reduce urinary tract injury during management of placenta accreta, increta and percreta. J Matern Fetal Neonatal Med. 2012; 25(4):329-34.

12. Lisa Allen, Eric Jauniaux, Sebastian Hobson, Jessica Papillon-Smith, Michael A. Belfort FIGO consensus guidelines on placenta accreta spectrum disorders: Nonconservative surgical management. Int J Gynecol Obstet. 2018;140:281-90.

13. Walker MG, Allen L, Windrim RC, Kachura J, Pollard L, Pantazi S, et al. Multidisciplinary management of invasive placenta praevia. J Obstet Gynaecol Can. 2013;35(5):417-425.

14. Palacios-Jaraquemada JM, Bruno CH, Clavelli WA. Morbid adherent placenta: prediction, diagnosis and management. Fetal Matern Med Rev. 2007;18(4):357-81

15. Yap YY, Perrin LC, Pain SR, Wong SF, Chan FY. Manual removal of suspected placenta accreta at caesarean hysterectomy. Int J Gynecol Obstet. 2008;100(2):186-87.

16. Esakoff TF, Handler SJ, Granados JM, Caughey AB. Placenta accrete management across the united states. J Matern Fetal Neonatal Med. 2012;25(6):761-5.

17. Ojala K, Perala J, Kariniemi J, Ranta P, Raudaskoski T, Tekay A. Arterial embolization and prophylactic catheterization for the treatment for severe obstetric haemorrhage. Acta Obstet Gynecol Scand 2005; 84(11):1075-80.

18. Arulkumaran S, Ng CS, Ingemarsson I, Ratnam SS. Medical treatment of placenta accreta with methotrexate. Acta Obstet Gynecol Scand 1986; 65(3):285-86.

19. Hays E, Ayida G, Crocker A. The morbidly adherent placenta: diagnosis and management option Curr Opin Obstet Gynecol. 2011;23(6):448-53.

20. Eller AG, Porter TF, Soisson P, Silver RM. Optimal management strategies for placenta accreta. $\mathrm{Br} \mathrm{J}$ Obstet Gynecol 2009 Apr; 116(5): 648-54.

21. Riggs JC, Jahshan A, Schiavello HJ. Alternative conservative management of placenta accreta. A case reports. J Reprod Med. 2000;45(7):595-8.

Cite this article as: Vyas RC, Patel PA, Shah S, Vala SN, Patel NB. Morbidly adherent placenta: management is real challenge. Int J Reprod Contracept Obstet Gynecol 2019;8:1091-5. 